\title{
NO BRASIL AS TENDENCIAS RELIGIOSAS CONTINUAM: DECLÍNIO CATÓLICO E CRESCIMENTO EVANGÉLICO ${ }^{1}$
}

\author{
Ari Pedro Oro ${ }^{2}$
}

\begin{abstract}
Resumo: Concernente ao Brasil, Sébastien Fath, em seu texto "Das margens ao mainstream: desafios sociais da ascensão evangélica, uma comparação transamericana”, reitera, acertadamente, duas tendências predominantes, a saber: o declínio católico e o crescimento evangélico. Este texto apresenta as principais reflexóes produzidas por cientistas sociais para explicar essa reconfiguração da paisagem religiosa que há algumas décadas está ocorrendo no país. Especialmente, analisa a questão acerca da possibilidade dos evangélicos suplantarem os católicos no Brasil, avança hipóteses sobre as duas linhas de força referidas, destacando que elas resultam de situaçóes internas e externas a cada uma das instituiçóes religiosas e, enfim, o texto apresenta algumas afinidades observadas nos campos evangélicos do Brasil e dos Estados Unidos.
\end{abstract}

Palavras-chave: Católicos; Evangélicos; Recenseamento Religioso; Brasil; Estados Unidos.

\begin{abstract}
Concerning Brazil, Sébastien Fath, in his text "From the margins to the mainstream: social challenges of the evangelical rise, a transamerican comparison", rightly reiterates two predominant tendencies: the Catholic decline and the Evangelical growth. This text presents the main reflections produced by social scientists to explain this reconfiguration of the religious landscape, that has been taking place in the country for some decades. In particular, it analyzes the question about the possibility of Evangelicals to supplant Catholics in Brazil, advances

1 Como citar: ORO, Ari Pedro. No Brasil as tendências religiosas continuam: declínio católico e crescimento evangélico. Debates do NER, Porto Alegre, v. 1, n. 37, p. 69-92, 2020.

2 Ari Pedro Oro é pesquisador associado ao Núcleo de Estudos da Religião da Universidade Federal do Rio Grande do Sul, Porto Alegre, Brasil. E-mail: arioro@uol.com.br.
\end{abstract}


hypotheses about the two lines of force mentioned, highlighting that they result from internal and external situations to each of religious and, finally, the text presents some affinities observed in the evangelical fields of Brazil and the United States.

Keywords: Catholics; Evangelicals; Religious Census; Brazil; United States.

Sébastien Fath nos brinda, em seu texto "Des marges au mainstream: enjeux sociaux de l'ascension évangélique; une comparaison transaméricaine”, com uma minuciosa análise da progressão do evangelismo norte-americano ocorrida no sul dos Estados Unidos entre os anos 1800 e 1850, que ensejou a criação da Bible Belt. O texto se quer comparativo com o Brasil, mas numa outra temporalidade, que cobre o arco de 1960 a 2010, não havendo aqui, porém, a mesma explanação aprofundada que se observa para a realidade norte-americana. Obviamente que seria demais esperar semelhante semeadura de dados e análises sobre o Brasil no espaço de um artigo. Porém, o colchão de informações apresentado sobre a situação norte-americana serve de suporte para várias e interessantes abordagens e indagaçóes pertinentes produzidas pelo autor sobre a realidade brasileira, embora envolva formaçóes socioculturais diferentes. As questóes levantadas por Fath versam tanto sobre o campo religioso, evangélico sobretudo, mas também, mais amplamente sobre as relaçóes entre religião e política, Igreja e Estado, tanto no Brasil quanto nos Estados Unidos.

Como o espaço de que disponho aqui é também limitado vou focar num tópico desenvolvido por Fath, supondo que o conjunto dos textos produzidos pelos colegas que comentam o texto do sociólogo francês possam ampliar as abordagens e dar conta dos vários questionamentos por ele produzidos. Embora Fath nos convoque a refletir sobre o que se passa no Brasil a partir de situaçôes observadas na realidade norte-americana, sem, obviamente, desconsiderar as idiossincrasias locais, de minha parte concentro este texto na questáo da reconfiguraçáo da paisagem religiosa brasileira caracterizada, como sustenta Fath, pelo declínio espetacular de indivíduos que se declaram católicos acompanhado pela ascensão vertiginosa do setor evangélico, o qual passou da condição de margem para mainstream. Trata-se de um main- 
stream composto de um combo que alcança a cultura, a mídia e a política, ocupando os evangélicos, no atual governo Bolsonaro, uma centralidade na esfera política nunca antes observada neste país ${ }^{3}$.

A razão pela escolha da reconfiguração da paisagem religiosa brasileira - caracterizada, como disse, fundamentalmente, pelo declínio católico e avanço evangélico - como foco do presente texto deve-se ao fato de estarmos diante de um fenômeno religioso único no mundo atual com essa robustez e envergadura.

\section{OS NÚMEROS CONFIRMAM: AS TENDÊNCIAS CONTINUAM}

Sébastien Fath inicia o artigo recordando que a recomposição da paisagem religiosa que ocorre no Brasil nos últimos cinquenta anos se caracteriza pelo declínio (espetacular) do catolicismo e pela ascensão (grandiosa) do evangelismo. Trata-se de uma afirmação que encontra sustentação estatística, baseada em dados oficiais do Instituto Brasileiro de Geografia e Estatística (IBGE) - colhidos a cada dez anos - que mostra, em porcentagem, a seguinte curva descendente de brasileiros que se identificam como católicos: 1970 (91,8), 1980 (89,2) 1990 (83,80), 2000 (73,77) 2010 (64,63). Já a curva evangélica, segundo a mesma fonte oficial, vai no sentido inverso. Ela é ascendente: 1970 (5,2 ), $1980(6,6) 1990$ (9,5), 2000 (15,4) 2010 (22,1).

Duas observaçóes iniciais se fazem aqui necessárias. Em primeiro lugar, há uma relação entre os dois movimentos religiosos que estão acontecendo no Brasil nas últimas décadas. Ou seja, um número significativo de indivíduos

3 Diga-se de passagem, como observa o jornalista Josias de Souza, que a "nova política" de Bolsonaro é alicerçada nas igrejas evangélicas e nos militares. Segundo ele: "Bolsonaro vê igrejas como diretórios partidários, pastores como cabos eleitorais. Projeta sua imagem nacionalmente sem vincular-se a superestruturas partidárias. Dos militares, ele extrai um apoio político capaz de estabilizar seu governo" (SOUZA, Josias de. Nova politica do capitão é feita de igrejas e militares. UOL, São Paulo, 1 mar. 2020. Disponível em: https://noticias.uol.com.br/colunas/josias-de-souza/2020/03/01/nova-politica-do-capitao-e-feita-de-igrejas-e-militares.htm. Acesso em: 1 mar. 2020.).

Debates do NER, Porto Alegre, ano 20, N. 37, P. 69-92, JAN./JUl. 2020 
(44\% segundo o Instituto Datafolha $)^{4}$ que engrossaram o campo evangélico provieram das fileiras católicas. De fato, como sublinha Mariano (2013, p. 120), o campo evangélico, sobretudo os pentecostalismos, constituem "o destino principal de seus ex-filiados" (do catolicismo). Assim sendo, como afirma Mafra (2014, p. 40), radica aqui uma linha de força que atravessa o holograma das religióes no Brasil": ela "se movimenta a partir do catolicismo em direção aos evangélicos pentecostais”. Neste sentido, Andrade (2014, p. 116) mostra que nas décadas de 1990 a 2010, portanto, durante vinte anos, cerca de 18 milhôes de católicos abandonaram a igreja a cada década e cerca de 13 milhôes de pessoas integraram-se ao segmento evangélico em cada uma das duas décadas. Ou seja, entre 1990 e 2010 os católicos caíram $1 \%$ ao ano enquanto que os evangélicos cresceram $0,7 \%$. A extensa desfiliação católica também revela que a origem da maioria de uma outra frente aberta no campo religioso brasileiro, os sem religião, também derivam do catolicismo. Esses, no Censo de 2000 somavam 7,3\% da população e subiram para 8,04\% no Censo de 2010. Assim sendo, como afirmam Almeida e Montero (2001, p. 97), o catolicismo funciona como uma espécie de "doador universal", de onde os pentecostalismos e os sem religião arregimentam boa parte dos seus fiéis.

Em segundo lugar, o crescimento evangélico no Brasil ocorre dentro do amplo segmento pentecostal, neo-pentecostal e renovado e não na sua

4 DATAFOLHA. 44\% dos evangélicos são ex-católicos. Datafolha, São Paulo, 28 dez. 2016. Disponível em: https://datafolha.folha.uol.com.br/opiniãopublica/2016/12/ 1845231-44-dos-evangélicos-sao-ex-catolicos.shtml. Acesso em: 1 mar. 2020.

5 Mafra (2014, p. 36) propóe a substituição da metáfora do mapa das religióes, bastante utilizado e repetido, pelo de holograma. Enquanto a primeira prevê "uma topografia unidimensional com fronteiras que ocasionalmente se sobrepóem e vazam”, a segunda contempla "unidades em constante movimento, com ramificaçóes chegando a ordens inimagináveis de extensôes de nós”.

Debates do NER, Porto Alegre, ano 20, N. 37, P. 69-92, JAN./JUl. 2020 
ala histórica (luterana, presbiteriana, batista e outras) ${ }^{6}$, cujas igrejas, de uma maneira geral, tem mantido, e algumas delas até diminuído, o número de fiéis ao longo das últimas décadas. Se no Censo de 2000 os evangélicos históricos e de missão somavam 4,1\% da população, no Censo de 2010 a porcentagem baixou para $4 \%$, ou seja, houve um pequeno decréscimo. Assim sendo, se o grande campo evangélico está aumentando no Brasil é por conta de uma acentuada pentecostalização do mesmo. Já o ramo histórico do protestantismo patina, segundo Marco Antônio de Oliveira (2014, p. 143), porque "o modelo de pastoral e de vida propostos [...] não conseguiram ainda estabelecer/construir uma ponte, ou até um bom diálogo, com a cultura brasileira". Além disso, segundo o mesmo autor, aquele protestantismo "é enamorado de uma visão teológica exclusivista e preconceituosa em relação às manifestaçóes culturais populares brasileiras" (Oliveira, 2014, p. 143).

Até agora apresentei dados que chegavam a 2010, ano do último recenseamento oficial realizado no Brasil. Porém, nos últimos anos alguns institutos privados continuaram a realizar levantamentos sobre o campo religioso brasileiro, entre eles o Instituto Datafolha, o qual, em dezembro de 2016, divulgou um levantamento que reforça o que os organismos oficiais têm detectado nas últimas décadas. Ou seja, o declínio católico continua acelerado, a tal ponto que naquela data os católicos chegavam à metade do país (50\%), enquanto os evangélicos alcançavam $29 \%$ da população, sendo $22 \%$ do segmento pentecostal e $7 \%$ do ramo histórico. Além disso, os sem religião somavam $14 \%$, seguidos dos espíritas (2\%), dos umbandistas (1\%),

6 A questão das classificaçóes do protestantismo no Brasil foi objeto de um estudo crítico de Giumbelli (2001). Nele, o autor relativiza as elaboraçóes analíticas propostas por "científicos" e "religiosos", evidenciando convergências e colaboraçôes entre eles. Especialmente, destaca como relevante menos a diferença entre os estudiosos do campo religioso e mais o que os distingue das posiçóes acionadas desde outras posiçôes sociais.

Debates do NER, Porto Alegre, ano 20, N. 37, P. 69-92, JAn./Jul. 2020 
dos seguidores do candomblé (1\%), dos ateus (1\%) e seguidores de outras religiōes $(2 \%)^{7}$

\section{O BRASIL SERÁ UM PAÍS EVANGÉLICO?}

Sem querer fazer um exercício de futurologia, incompatível com a prática científica, alguns estudiosos tem se indagado ou foram provocados a se colocar a pergunta acerca do futuro religioso do Brasil. Esta é, principalmente, a pergunta mais recorrente: se as tendências continuarem por mais algumas décadas os evangélicos suplantarão os católicos?

Esta é uma questão controvertida e polêmica, surgida ainda na década de 1990, formulada acerca do avanço evangélico na América Latina. Lembremo-nos, neste sentido, que D. Martin (1990) levantava a hipótese de uma "uma nova reforma protestante" na América Latina e que D. Stoll (1990) se indagava se a América Latina não estava se tornando protestante (Stoll, 1990).

Acerca do futuro religioso brasileiro obviamente que os analistas divergem, além de se mostrarem prudentes, em avançar prognósticos, pois em termos de mobilidade religiosa há ritmos e velocidades que podem mudar, tetos que podem ser alcançados e estagnados etc. Por isso mesmo, há autores que apontam limites nas linhas de força que estamos analisando pois elas podem se estabilizar. Assim, por exemplo, Andrade (2014, p. 115-116) avança que os dados atuais não permitem extrapolaçóes no sentido de que "o Brasil se tornará brevemente uma nação majoritariamente evangélica", sendo mais plausível, continua o autor, "que nas próximas décadas ocorra certa estabilização dos números [...]".

Paul Freston, em texto escrito em 2010, também sustenta que "pelas tendências atuais nunca haverá uma maioria protestante no Brasil” (Freston,

7 DATAFOLHA. 44\% dos evangélicos são ex-católicos. Datafolha, São Paulo, 28 dez. 2016. Disponível em: https://datafolha.folha.uol.com.br/opiniãopublica/2016/12/ 1845231-44-dos-evangélicos-sao-ex-catolicos.shtml. Acesso em: 1 mar. 2020.

Debates do NER, Porto Alegre, ano 20, N. 37, P. 69-92, JAN./Jul. 2020 
2010 , p. 24). Isto porque, prossegue o sociólogo inglês, “o declínio católico terá um limite [...], o protestantismo atualmente recebe pouco mais de uma em cada duas pessoas que abandonam o catolicismo [...] a Igreja Católica está aprendendo (lentamente, é verdade) a competir melhor e a diversificar o seu apelo" (Freston, 2010, p. 24). Além disso, a imagem social evangélica também pode contribuir para frear a atração de fiéis devido a escândalos, lideranças autoritárias, promessas não-cumpridas, imagem política negativa. Diante desse cenário, Freston (2010) projeta para o Brasil um teto futuro de católicos em torno de $40 \%$ e de $35 \%$ de evangélicos.

Mas, há prognósticos que vão em direção contrária. Assim, a prestigiada revista Pesquisa FAPESP, que elegeu o fenômeno evangélico como matéria de capa de sua edição de dezembro de 2019, afirma que mantida a tendência atual do crescimento evangélico "em 2022 [...] os católicos devem representar menos de metade da população brasileira” (Queiroz, 2019, p. 14).

Na mesma direção, o pesquisador em demografia do IBGE, José Eustáquio Alves, projeta que caso o ritmo das tendências atuais sejam mantidas, em 2022 os católicos encolheriam para menos de 50\% e em 2032 seriam $38,6 \%$ da população. Enquanto isto, em 2032 os evangélicos alcançariam $39,8 \%$, ou seja, superariam os católicos, mas não seriam a maioria da população brasileira. Esta, a maioria absoluta, segundo Alves, seria alcançada próximo de 2050, mas, relativizando afirma que somente "o futuro dirá"

Paul Freston destaca, com razão, que - embora preveja um teto no crescimento protestante no Brasil, como vimos acima - se vier a acontecer a "transição católica", isto é, a queda da porcentagem da população que se declara católica para menos da metade, será "um momento simbolicamente importante” (Freston, 2010, p. 14) em razão da importância histórica do catolicismo no país e no subcontinente americano.

8 BALLOUSSIER, Anna Virginia. Evangélicos podem desbancar católicos no Brasil em pouco mais de uma década. Folha de S. Paulo, São Paulo, 14 jan. 2020. Disponível em: https://www1.folha.uol.com.br/poder/2020/01/evangélicos-podem-desbancar-catolicos-no-brasil-em-pouco-mais-de-uma-decada.shtml?origin=uol. Acesso em: 1 mar. 2020.

Debates do NER, Porto Alegre, ano 20, N. 37, P. 69-92, JAN./JUl. 2020 
Pessoalmente, concordo com R. Mariano (1999) quando sustenta que os pentecostalismos brasileiro e latino-americano têm perdido o seu caráter modernizador e abandonado a rejeição ascética do mundo, características estas do protestantismo da Reforma europeia e da colonização dos Estados Unidos. Este protestantismo, aliás, continua o sociólogo da USP, se, talvez, no passado foi promotor de modernidade, há muito tempo que não o é mais, pois fora tomado de um conservadorismo teológico e de uma ética pietista. Assim sendo, se estatisticamente dentro de algumas décadas o Brasil se tornar evangélico, cuja probabilidade não está descartada, como vimos, não será evangélico nos moldes do protestantismo histórico, mas evangélico com amplo predomínio de um pentecostalismo sincretizado, abrasileirado, tragado pela "antropofagia brasileira" e, consequentemente, mais aculturado e desprovido de um "potencial para transformar a cultura, os valores e a economia [...]" (Mariano, 1999, p. 90).

\section{FATORES DO DECLÍNIO CATÓLICO \\ E DO CRESCIMENTO EVANGÉLICO-PENTECOSTAL}

As explicações são múltiplas, variadas e complexas, acerca das linhas de força acima referidas e que marcam o campo religioso brasileiro das últimas décadas. Avanço aqui somente algumas abordagens analíticas, iniciando pelo recuo do catolicismo na sociedade brasileira.

Steil e Toniol chamam a atenção, inicialmente, para o fato de que a redução constante de indivíduos que se identificam como católicos é acompanhada do declínio expressivo dos que buscam os sacramentos na Igreja, bem como da perda da "hegemonia católica sobre a cultura e a produção de valores e significados [...]” (Steil; Toniol, 2014, p. 14).

No mais, para esses e outros analistas, a desfiliação do catolicismo reside em problemas internos e externos à própria Igreja. O problema interno mais recorrente aponta para a sua estrutura rígida e sua hierarquia rigorosa, que dificultam mudanças e adaptação aos novos tempos, tanto em termos 
tecnológicos quanto doutrinários, passando pelos ritualísticos. Neste sentido, Steil e Toniol destacam um problema estrutural da instituição católica que afeta a cultura e o catolicismo popular tradicional. Para eles, "em relação à cultura, observamos que o catolicismo encontra cada vez menos os recursos e as instituiçôes tradicionais locais para sua reprodução como religião" (Steil; Toniol, 2014, p. 13). Já em relação ao catolicismo das tradiçóes populares, "constatamos uma quebra dos laços de complementaridade que legitimavam a Igreja Católica como representante da extensa população de pobres que se declaravam católicos por tradição no espaço politico e social" (Steil; Toniol, 2014, p. 13-14).

Demais autores apontam outros problemas pontuais da Igreja Católica. Assim, por exemplo, C. Mafra (2009) sustenta que o catolicismo mostrou-se incapaz de oferecer respostas adequadas e eficazes para as novas condiçóes vividas pelos indivíduos nas metrópoles. Andrade (2014, p. 117), por sua vez, afirma que "a Igreja Católica parece cada vez mais incapaz de oferecer uma experiência espiritual que atenda às demandas colocadas na contemporaneidade".

No entanto, o recuo do catolicismo na sociedade brasileira - mas não somente aqui - não se restringe aos limites internos à própria instituição. Os analistas também inscrevem a desfiliação católica num aspecto da modernidade religiosa, qual seja, a autonomia do indivíduo em suas opçóes religiosas. É o caso, novamente, das análises de Steil e Toniol (2014) para quem, o declínio católico está também relacionado com o fato de os indivíduos tenderem menos a seguir uma religião por força da tradição, imposta pela cultura e mais como uma opção pessoal de escolherem livremente uma comunidade de fé. Assim, o argumento dos autores é de que está ocorrendo hoje no Brasil uma desinstitucionalização e uma destradicionalização, ou seja, "um processo de transformação da cultura católica que tem impedido a transmissão do catolicismo por via da tradição" (Steil; Toniol, 2014, p. 16). Trata-se, portanto, de uma crise do catolicismo resultante das transformaçóes "que vêm se operando no âmbito da própria cultura e da forma 
como a religião se configura nos tempos atuais no contexto moderno" (Steil; Toniol, 2014, p. 17) ${ }^{9}$.

Silvia Fernandes também sugere que a chave analítica do individualismo moderno constitui uma entre outras possibilidades explicativas do entendimento do catolicismo atual. Especialmente, aponta ela,

[...] o catolicismo brasileiro precisa ser pensado em suas interfaces com o dia a dia das pessoas, seja nos espaços fortemente marcados pela expansão urbana e suas consequências, seja em pequenas localidades nas quais a tradição pode ser combinada com novas demandas subjetivas e materiais (Fernandes, 2014, p. 63).

Pessoalmente, acerca da situação atual que distancia as pessoas da igreja católica, gostaria de colocar em tela alguns poucos aspectos resultantes de observações etnográficas. Em primeiro lugar, no meio urbano é visível nas igrejas católicas a frequência em seus rituais de uma membresia composta majoritariamente por idosos. Isto significa que, se essa tendência se mantiver, com o passar do tempo, na medida em que os idosos desaparecerem, diminuirá também o número de frequentadores das igrejas. Em segundo lugar, um levantamento não exaustivo mostra que as pessoas que se dirigem à Igreja Católica dizem não encontrar ali conforto às suas angústias, pois os enunciados que ouvem do clero não dialoga com suas necessidades e subjetividades. Ou seja, o agente católico parece mostrar-se incapaz de produzir um discurso adequado e que venha ao encontro das situaçóes existenciais vividas pelas pessoas. Ao contrário disso, o sermáo católico, por exemplo, revela-se demasiadamente teológico, doutrinário, racional e dirigido para mentes ilustradas. Muitas vezes parece que o padre fala para teólogos, faz uso de um linguajar erudito, bem distante do vernáculo usado pelo povo em geral. Enfim, a maioria dos templos católicos tem dificuldade de se

9 Sustentam os autores, ainda, que a crise atual é mais do catolicismo e menos da Igreja Católica, a qual, no Brasil, conseguiu aumentar o número de novas paróquias e viu aumentar o percentual de padres por habitantes (Steil; Toniol, 2014, p. 19-20).

Debates do NER, Porto Alegre, ano 20, N. 37, P. 69-92, JAN./Jul. 2020 
modernizar, com tecnologia de som e imagem de qualidade, por exemplo, e de proporcionar conforto aos fiéis, como ar condicionado e poltronas confortáveis. Toda essa estrutura sólida e pesada da igreja, presa no tempo, demasiadamente tradicional e mesmo arcaica, associada a uma ordem hierárquica muitas vezes intransigente e autoritária, além de dificultar a adequação da Igreja aos tempos modernos e às expectativas das pessoas, ingressa no rol de itens que contribui para afastar as pessoas em geral, e os jovens em particular, das suas fileiras.

Há mais de vinte anos, Pierre Sanchis sintetizava a situação acima, concernente à igreja católica, com as palavras: "secura e greve de vida" e "frieza de tantas assembleias dominicais católicas" (Sanchis, 1994, p. 60).

É possível que a Renovação Carismática Católica e o fenômeno dos padres cantores, com sua presença na mídia e um dispositivo ritualístico mais alegre e um discurso mais simples e palatável aos fiéis, que recupera, inclusive, a dimensáo emocional, algo recorrente nos pentecotalismos, estejam contribuindo para reduzir o ritmo do declínio católico e quiçá exercendo uma atração também sobre os jovens. Mas, isto ainda será objeto de estudo e desde já há estudiosos, como R. Mariano (2013, p. 120), para quem a reação católica capitaneada pela RCC não surtiu efeito, ou seja, "não conseguiu, sobretudo, refrear a expansão pentecostal, destino principal de seus (católicos) ex-filiados".

Seja como for, diante do enfraquecimento do catolicismo na cena nacional, devido, como vimos, a motivos internos e externos à instituição, autores como Steil e Toniol (2014, p. 12) se perguntam se hoje ainda se pode afirmar ser o catolicismo "uma das referências religiosas fundadoras da nacionalidade e da cultura nacionais". E respondem: "Com certeza, estamos longe desse contexto cultural em que a tradição católica podia ser firmada como fundadora da nação brasileira [...]" (Steil; Toniol, 2014, p. 12).

Vejamos agora algumas contribuiçôes analíticas acerca do avanço evangélico, sobretudo pentecostal e neopentecostal. Estamos, novamente, diante de um capítulo denso e complexo, porque o pentecostalismo não é unívoco (Miguez, 1997). Ao contrário, ele constitui um movimento religioso tão 
polimorfo e diverso que Marion Aubrée (1998) chama-o de "constelação" evangélico-pentecostal.

Iniciado como uma religião das periferias das cidades, nas primeiras décadas do século XX, caracterizado pela mínima participação "no mundo" e exigindo dos seus fiéis extrema rigidez de conduta, nos últimos tempos o pentecostalismo mudou: seus templos foram erguidos também nos centros urbanos, sua membresia atingiu também as camadas médias e não mais somente os pobres dos meios urbanos - embora estes ainda constituam a maioria dos fiéis - e sua participação na sociedade agora alcança a cultura, as mídias e a política.

Avanço algumas pistas teóricas propostas por analistas visando explicar o avanço evangélico, sobretudo pentecostal. R. Mariano recorda que os pioneiros do estudo do pentecostalismo latino-americano o consideraram "como estratégia de ajustamento social dos indivíduos dos estratos pobres e marginalizados, sobretudo dos migrantes de origem rural” (Mariano, 1999, p. 100). Mariano está se referindo às duas análises hoje tidas como clássicas da expansão pentecostal na América Latina, realizadas pelo antropólogo alemão E. Willems (1967) e pelo sociólogo suíço L. D’Epinay (1970).

Outros autores avançaram suas análises na esteira dos pioneiros. Assim, por exemplo, referindo-se sobre a expansão pentecostal na América Latina, Cristian Parker (1986) reforça que o êxodo rural e a migração para as cidades, decorrentes do processo de urbanização e de industrialização, colocou uma massa humana no caminho das igrejas, a qual passou a encontrar nelas consolo e conforto diante dos problemas enfrentados na nova realidade vivida. Por seu turno, R. Cesar Fernandes (1994), referindo-se mais especificamente ao pentecostalismo brasileiro, considera ser ele uma opção sobretudo dos pobres, além de uma iniciativa que independe das elites sociais, estar em franca expansão e ser, apesar e após sua origem estrangeira, uma religiáo brasileira.

Outras dimensóes já presentes nas análises dos pioneiros foram reforçadas por outros autores. Por exemplo, C. Mariz (1994) sublinha que o pentecostalismo ajuda os pobres a enfrentarem a pobreza, a se libertarem do 
alcoolismo e das drogas, melhorando, assim, a autoestima enquanto conversos. Já R. Mariano aprofunda essa análise, evidenciando outras dimensões do pentecostalismo. Para ele,

O sucesso pentecostal fundamenta-se extensamente no milagre, na magia, na experiência extática, no transe, no pietismo ou na manipulação da emoção transbordante e desbragada, práticas desprezadas e reprimidas pelas igrejas Católica e Protestante. Oferece magia e catarse para as massas. E uma boa pitada do velho moralismo cristão (Mariano, 1999, p. 107).

A dimensão emocional, evidenciada por Mariano, é central na análise que A. Corten realiza sobre o pentecostalismo. Para ele, o pentecostalismo constitui um espaço de expressão da emoção. Assim, "não é a tradição que os reúne [os crentes], é a vontade de proclamar suas emoçôes [miséria, doença, violência]" (Corten, 1995, p. 12).

Por seu turno, Silvia Fernandes (2014) avança outra dimensão explicativa para o avanço pentecostal. Trata-se da relação entre cotidiano e território, ou seja, a autora aponta a territorialidade como uma chave importante na dinâmica sociorreligiosa brasileira. Neste sentido, em sua perspectiva, a importante implantação de novas igrejas e templos evangélicos no espaço urbano constitui um fator não desprezível da adesão das pessoas a este segmento religioso.

Já Andrade (2014, p. 120) vê proximidade entre pentecostalismo e catolicismo popular. Ou seja, levanta a hipótese de que as comunidades pentecostais oportunizam a recuperação da memória de um modo de ser religioso presente no catolicismo popular, marcado por intensidades de rezas e bênçãos e da autonomia do fiel na vivência de sua fé. Em outras palavras, o pentecostalismo dialoga e recupera experiências religiosas próprias da chamada religiosidade popular e/ou do catolicismo popular.

A dimensão da religiosidade popular é também sublinhada por A. Frigerio para explicar o êxito pentecostal na América Latina. Com efeito, o antropólogo argentino póe em relevo algumas características dessa religio- 
sidade presente nas igrejas pentecostais e que geralmente são desaprovadas pela hierarquia da Igreja Católica. São elas: "la posibilidad de la intervención divina en la vida cotidiana de las personas, la comunicación directa con la divindad tanto durante los rituales como fuera de estos y la importancia de lo emotivo en esta comunicación [...]" (Frigerio, 2019, p. 49). Frigerio também destaca que o êxito da Umbanda e da Renovação Carismática Católica - mas em proporção bem inferior do que o pentecostalismo também se deve à continuidade cultural que estas religióes mantem com a religiosidade popular latino-americana (Frigerio, 2019, p. 50).

Pessoalmente destaquei como explicação para o avanço pentecostal (Oro, 1995, 2011) algumas dimensóes internas aos próprios pentecostalismos, a saber: sua dinâmica social (especialmente sua capacidade de acolhida dos fiéis e de criação de um ambiente agradável e confortável para eles); sua organização interna (com distribuição de tarefas e papéis que envolvem um número significativo de membros); sua ritualística (sobretudo a produção performática, que envolve mediaçóes materiais capazes de contribuir para uma experiência profunda da vivência do sagrado); e sua narrativa cosmológica (que faz sentido para os seus fiéis, pois dialoga com concepçóes culturais e simbólicas significativas e eficazes para eles).

\section{ESTADOS UNIDOS E BRASIL:}

\section{ALGUMAS AFINIDADES NO CAMPO RELIGIOSO}

De posse dos números e das análises acima apresentados, retomo a proposta comparativa de Sébastien Fath, pois podemos, agora, colocar em evidência algumas afinidades entre o campo religioso norte-americano e brasileiro. Iniciemos pela observação realizada pelo sociólogo e teólogo brasileiro Paulo Fernando Carneiro de Andrade (2014), para quem em ambos os países a secularização não produziu ateísmo, mas trânsito e migração religiosa, diferentemente da Europa onde o ateísmo abrange cerca de 18\% 
da população, bem distante do $1 \%$ da população brasileira e dos 3,1\% nos Estados Unidos, segundo dados recentes ${ }^{10}$.

Andrade chama a atenção para outras duas proximidades entre Estados Unidos e Brasil. Em primeiro lugar, "Lá (Estados Unidos), também, como aqui (Brasil), a secularização fez crescer a expressão pentecostal, o trânsito religioso e formas de vivência religiosa autônoma, sem vinculação institucional" (Andrade, 2014, p. 114). Em segundo lugar, "Como Igreja, é a Católica, lá como aqui que sofre mais o processo de desfiliação e trânsito, perdendo fiéis tanto para outras Igrejas cristâs como para o grupo 'sem religião"” (Andrade, 2014, p. 114-115).

Outras analogias podem ser acrescentadas. Tanto no Brasil quanto nos Estados Unidos a área cristã é hegemônica, alcançando, segundo dados atuais, 70,6\% nos Estados Unidos (sendo 49,8\% evangélicos, dos quais 25,4\% são pentecostais e $20,8 \%$ católicos) ${ }^{11}$ e $79 \%$ no Brasil, segundo os dados acima apresentados, resultantes da pesquisa conduzida pelo Instituto Datafolha (sendo $50 \%$ católicos e $29 \%$ evangélicos, dos quais 22\% pentecostais), isto malgrado a existência de uma diversidade religiosa observada em ambos os países. Observa-se, portanto, uma proximidade numérica de cristãos em ambos os países, mas com uma inversão denominacional: enquanto a maior expressão cristã é evangélica nos Estados Unidos ela é católica no Brasil, ao menos por enquanto, como vimos. Outra diferença entre nós e os Estados Unidos reside no fato de que no país do norte a diversidade religiosa é histórica, datando de séculos, como mostrou Sébastien Fath em seu texto, enquanto que a brasileira é recente pois aqui o catolicismo se impôs como religião dominante durante séculos.

De fato, vale recordar que em nosso país durante os períodos colonial (1500-1822) e imperial (1822-1889), o catolicismo foi considerado religiáo

${ }^{10}$ PEW RESEARCH CENTER. Religious Landscape Study. Pew Research Center, Washington, DC, 3 mar. 2020. Disponível em: https:/www.pewforum.org/religious-landscape-study/. Acesso em: 27 fev. 2020.

11 Ibid. 
de Estado. Foi somente na constituição republicana de 1891 que a laicidade foi implantada, isto é, firmou-se legalmente a separação entre Igreja e Estado, pondo fim ao monopólio católico.

A história mostrou, porém, que na prática a nova configuração legal não impediu a continuação da proximidade entre Igreja Católica e Estado, recebendo ela uma discriminação positiva, diferentemente de outras religiôes que receberam uma discriminação negativa, malgrado a liberdade religiosa assegurada desde a origem da República. Foi somente a partir das décadas de 1960-1970, com o início do avanço pentecostal, que a diversidade religiosa começou a se instalar realmente no Brasil. Mas, como disse, ela é predominantemente cristấ, uma vez que as religióes mediúnicas (espiritismo, afro-brasileiras), orientais e outras somam, no seu conjunto, cerca de $6 \%$ da populaçáo brasileira, e os sem religiáo, $14 \%$, enquanto que nos Estados Unidos os náo-cristáos somam 5,9\%, outras religiôes 1,5\% e os sem religiáo (unaffiliated) 22,8\%. Aqui, notamos novamente alguma proximidade entre Estados Unidos e Brasil, ou seja, a porcentagem de não-cristáos gira em torno de $6 \%$ em ambos os países. Já a porcentagem dos sem religiáo ou dos náo filiados religiosamente é maior nos Estados Unidos do que no Brasil.

Outra afinidade entre a realidade religiosa e cultural norte-americana e a brasileira reside no fato de que em ambos os países vigora a separaçáa Igreja e Estado mas não se prevê a expulsão da religiáo do espaço público. De fato, no Brasil, a laicidade, como disse acima, que oficialmente separou Igreja e Estado, não foi acompanhada da secularização da sociedade, ou seja, "a separação entre Estado/Igreja nunca deu como resultado a saída da religiāo da vida pública" (Camurça, 2018, p. 301), sendo esta considerada a "laicidade à brasileira" (Mariano, 2011).

Ora, a "laicidade à brasileira" mantem, justamente, semelhança com o modelo norte-americano da religious freedom. Esta, segundo Diotallevi (2010, p. 27), "da vida a un régimen de separación entre poderes políticos y poderes religiosos que no prevê la expulsión de la religión del espacio público [...]. En consecuencia, la política no tiene el monopólio del espacio público". 
A imbricação entre religião e política está mais do que nunca na ordem do dia, tanto nos Estados Unidos quanto no Brasil. Trata-se de uma proximidade que ocorreu "no tempo da política", onde Trump contou com elevado apoio evangélico em sua eleição ${ }^{12}$, o mesmo ocorrendo com Bolsonaro, no Brasil. No caso brasileiro, analistas mostraram que sem os votos dos evangélicos Bolsonaro não teria sido eleito presidente (Almeida, 2019). Ainda relativamente ao Brasil, para mostrar ou selar a aliança firmada entre o atual governo federal e o setor evangélico conservador, sobretudo renovado, pentecostal e neopentecostal, em detrimento do evangélico histórico (luteranismo, anglicanismo, presbiterianismo) e, sobretudo, do catolicismo, Bolsonaro buscou no segmento evangélico três Ministros de Estado e o Advogado Geral da Uniāo ${ }^{13}$, acenando, inclusive, que irá em breve indicar

${ }^{12}$ Os eleitores evangélicos brancos votaram majoritariamente em Donald Trump (numa relação de 81 a 16 por cento). É o maior índice desde 2004, quando George W. Bush recebeu $78 \%$ dos votos evangélicos. EVANGÉLICOS brancos votaram majoritariamente em Trump. Instituto Humanitas Unisinos, São Leopoldo, 10 nov. 2016. Disponível em: http://www.ihu.unisinos.br/78-noticias/562158-evangélicos-brancos-votaram-majoritariamente-em-trump. Acesso em: 27 fev. 2020.

${ }^{13}$ São eles: Damares Alves, pastora da Igreja Quadrangular e da Igreja Batista Lagoinha, Ministra da Mulher, da Família e dos Direitos Humanos do Brasil; Onyx Lorenzoni, membro da Igreja Luterana, ex-Ministro Chefe da Casa Civil e agora ministro da Cidadania e Marcelo Alvaro Antonio, membro da Igreja Cristã Maranata, Ministro do Turismo. Já o advogado-geral da União, André Luiz de Almeida Mendonça, é pastor de uma Igreja Presbiteriana, em Brasília e tido, nos bastidores, como futuro ministro do STF. 
para uma vaga no Supremo Tribunal Federal (STF) "alguém terrivelmente evangélico" (Oro, 2020, no prelo) ${ }^{14}$.

Sobre este último item importa frisar que nem aqui nem em qualquer parte do mundo democrático a variável religiosa deve ser uma condição para indicação e escolha de alguém para ocupar uma cadeira na mais alta corte jurídica do país. Ser religioso, ou não, é irrelevante, pois os requisitos para uma vaga no STF, segundo proclama a constituição nacional, é ser detentor de "reputação ilibada" e de "notável saber jurídico".

É claro que no caso do Brasil Bolsonaro corteja o setor evangélico, por um lado, para continuar a desfrutar do apoio político ao seu atual governo, tanto dos fiéis (eleitores) quanto da Frente Parlamentar Evangélica, também conhecida como Bancada Evangélica, no Congresso Nacional ${ }^{15}$, e, por outro lado, para ajudá-lo a obter um novo mandato na presidência da república. Isto tudo, evidentemente, não sem assegurar aos evangélicos, em troca, a possibilidade de desfrutarem das benesses do Estado, como isenção

${ }^{14}$ Diga-se de passagem, e a título de curiosidade, que atualmente os vínculos religiosos dos membros do Supremo Tribunal Federal do Brasil são os seguintes: 7 são católicos (Carmen Lucia, Dias Toffoli, Edson Fachin, Marco Aurélio Mello, Gilmar Mendes, Ricardo Lewandowski e Alexandre de Moraes; 2 são judeus (Luís Roberto Barroso e Luiz Fux) e 2 outros (Celso de Mello e Rosa Weber) não informaram suas religióes. Já nos Estados Unidos 5 ministros são católicos: John Roberts (presidente da corte), Clarence Thomas, Samuel Alito, Brett Kavanaugh e Sonia Sotomayor; 3 são judeus: Sthepen Breyer, Ruth Ginsburg e Elena Kagan. Enfim, Neil Gorsuch, foi criado no catolicismo, mas frequenta a Igreja Episcopal. Portanto, se no passado nos Estados Unidos vários ministros evangélicos integraram a Suprema Corte, e na atualidade um deles se filia a esta corrente religiosa, no Brasil não há notícias de um ministro evangélico no STF. A dinâmica de escolha de juízes ou ministros em ambos os países é a mesma: eles são escolhidos pelo presidente e confirmados pelo Senado Federal.

15 Trata-se de uma organização supra-partidária, surgida na Constituinte de 1986, que reúne evangélicos de diferentes denominaçôes que geralmente atua como grupo de pressão política somente quando está em discussão e debate projetos e questôes de ordem moral que consideram atentar contra os valores cristãos. Das últimas eleiçóes majoritárias de 2018 saiu uma bancada evangélica formada por 82 deputados e 9 senadores. Trata-se do mais alto índice de políticos identificados como evangélicos no Congresso Nacional. 
de impostos, exploração de mídias e apoio financeiro em suas iniciativas, sobretudo assistenciais.

Em seu texto Fath também menciona a importância do voto evangélico na eleição de Bolsonaro, mas chama a atenção - a partir de uma observação de Oscar Calavia Saez - de que o Partido dos Trabalhadores, durante os mandados de Lula e Dilma Rousseff, também mantiveram sólidas relaçōes com os evangélicos. Assim sendo, afirma Fath, "não se trata de um "terremoto evangélico" conservador (como) anunciado por certas mídias". Neste particular, Fath tem parcialmente razão, pois no passado, mesmo nos governos do PT, a presença evangélica na política brasileira não possuía a mesma robustez observada na atualidade. Ou seja, com a chegada de Bolsonaro no poder a presença evangélica subiu para um outro patamar. Agora os evangélicos integram o centro do poder, ocupam o primeiro escaláo do governo, na condição de ministros de Estados, são interlocutores privilegiados, até mesmo conselheiros, do atual governo. Agora o governo federal mantem com os evangélicos uma parceria estreita, a tal ponto que as principais iniciativas governamentais, mesmo os projetos de lei e as medidas provisórias, de alguma maneira passam previamente pela consulta a algumas lideranças evangélicas que se encontram fora e dentro do Parlamento. Isto significa que nunca como no governo de Bolsonaro os evangélicos ocuparam táo elevado protagonismo político, assentado, como disse, em interesses mútuos, dos evangélicos e do atual governo federal.

\section{CONCLUSÃO}

Elenquei, neste texto, algumas razóes que explicam a reconfiguraçáo religiosa brasileira, caracterizada, como enfatizou Sébastien Fath em seu texto, sobretudo, por duas linhas de força que se fortalecem cada vez mais nas últimas décadas, a saber: o recuo de indivíduos que se dizem católicos e a vertiginosa expansão daqueles que se consideram evangélicos. As razóes, 
como vimos, apontam para situaçóes internas e externas a cada uma das instituiçốes religiosas.

Acerca dessa questão, entre outros, três aspectos precisam ser reforçados neste momento. Em primeiro lugar, a análise das tendências acima constatadas mostrou que é preciso ir além das consideraçôes acerca dos méritos e dos deméritos das instituiçóes religiosas e levar em conta um aspecto relevante da modernidade religiosa, qual seja, a "intensificação do processo de individualização que comporta a experimentação, a diversificação e, portanto, a mobilidade e a fluidez no que se refere aos modos de pertencer, crer e reinventar a própria identidade religiosa” (Fernandes, 2014, p. 42).

Em segundo lugar, como destaca Ricardo Mariano (1999, p. 110), é relevante sublinhar que o protestantismo que cresce exponencialmente no Brasil é aquele do segmento pentecostal e neopentecostal, ou seja, "uma religiáo que cada vez mais deita raízes em nossa sociedade e é por ela influenciada num processo de assimilação mútua”. Esse pentecostalismo brasileiro "vai adquirindo fisionomia cada vez menos 'protestante" (Mariano, 1999, p. 110).

Enfim, como mostrei em outro lugar (Oro, 2011), o avanço evangélico-pentecostal não incide somente sobre o campo religioso brasileiro. Como Pierre Sanchis (1994, p. 63) destacou, "ele implica um desafio a uma tradição cultural, precisamente porque dessa tradição ele sabe reencontrar algumas das linhas mestras". Ou seja, os pentecostalismos possuem a capacidade de dialogar com elementos culturais centrais da vida religiosa e cultural brasileira, conseguindo, desta forma, como mostrou Sébastien Fath, sair da margem para o mainstream. Por isso mesmo, os pentecostalismos marcam forte presença no campo religioso, mas também nos meios de comunicação de massa e na política brasileira. Assim sendo, trata-se de um novo ator religioso que ocupou um lugar de destaque no espaço público brasileiro, desalojando, ao menos parcialmente, a Igreja Católica do confortável lugar histórico que ocupou nesses domínios no Brasil. 


\section{REFERÊNCIAS}

ALMEIDA, Ronaldo de. Bolsonaro presidente: conservadorismo, evangelismo e a crise brasileira. Novos Estudos Cebrap, São Paulo, v. 38, n. 1, p. 185-213, 2019.

ALMEIDA, Ronaldo de; MONTERO, Paula. Trânsito religioso no Brasil. São Paulo em Perspectiva, São Paulo, v. 15, n. 3, p. 92-101, 2001.

ANDRADE, Paulo Fernando Carneiro de. O Censo de 2010 e as religióes no Brasil: reflexôes teológicas em uma perspectiva católica. In: BINGEMER, Maria Clara Lucchetti; ANDRADE, Paulo Fernando Carneiro de (org.). $O$ censo e as religióes no Brasil. Rio de Janeiro: Ed. PUC-Rio: Reflexão, 2014. p. 111-122.

AUBRÉE, Marion. La vision de la femme dans la "constellation" pentecôtiste. Cahiers du Brésil Contemporain, Paris, n. 35/36, p. 231-246, 1998.

CAMURÇA, Marcelo. Laicidad a la brasileña. In: BLANCARTE, Roberto (ed.). Diccionario de religiones en América Latina. Ciudad de México: El Colegio de México, 2018. p. 293-303.

CORTEN, André. Os pobres e o Espírito Santo: o pentecostalismo no Brasil. Petrópolis: Vozes, 1995.

D'EPINAY, Christian Lalive. O refúgio das massas. Rio de Janeiro: Paz e Terra, 1970.

DIOTALLEVI, Luca. Alternativas a la laïcité: para un conocimiento menos augusto de la cultura europea y de su dimensión cristiana. Ciencias Sociales y Religion/Ciências Sociais e Religiâo, Campinas, v. 12, n. 13, p. 15-36, 2010.

FERNANDES, Rubem Cesar. Governo das almas: as denominações evangélicas no Grande Rio. In: ANTONIAZZI, Alberto et al. Nem anjos nem demônios: interpretaçóes sociológicas do pentecostalismo. Petrópolis: Vozes, 1994. p. 163-203. 
FERNANDES, Silvia Regina Alves. Católicos e catolicismo(s) no Brasil: dinamizando os dados censitários. In: BINGEMER, Maria Clara Lucchetti; ANDRADE, Paulo Fernando Carneiro de (org.). O censo e as religióes no Brasil. Rio de Janeiro: Ed. PUC-Rio: Reflexão, 2014. p. 43-66.

FRESTON, Paul. As duas transições futuras: católicos, protestantes e sociedade na América Latina. Ciencias Sociales y Religión/Ciências Sociais e Religião, Campinas, v. 12, n. 12, p. 13-30, 2010.

FRIGERIO, Alejandro. La experiencia religiosa pentecostal. Nueva Sociedad, Buenos Aires, n. 280, p. 47-54, 2019.

GIUMBELLI, Emerson. A vontade do saber: terminologias e classificações sobre o protestantismo brasileiro. Religiáo \& Sociedade, Rio de Janeiro, v. 21, n. 1, p. 87-119, 2001.

MAFRA, Clara. Distância territorial, desgaste cultural e conversão pentecostal. In: MAFRA, Clara; ALMEIDA, Ronaldo de (org.). Religióes e cidades: Rio de Janeiro e São Paulo. São Paulo: Terceiro Nome, 2009. p. 69-89.

MAFRA, Clara. Números e narrativas. In: BINGEMER, Maria Clara Lucchetti; ANDRADE, Paulo Fernando Carneiro de (org.). O censo e as religióes no Brasil. Rio de Janeiro: Ed. PUC-Rio: Reflexão, 2014. p. 31-42. MARIANO, Ricardo. Laicidade à brasileira: católicos, pentecostais e laicos em disputa na esfera pública. Civitas, Porto Alegre, v. 11, n. 2, p. 238-258, 2011.

MARIANO, Ricardo. Mudanças no campo religioso brasileiro no Censo 2010. Debates do NER, Porto Alegre, ano 14, n. 24, p. 119-137, jul./dez. 2013.

MARIANO, Ricardo. O futuro não será protestante. Ciencias Sociales y Religión/Ciências Sociais e Religiāo, Porto Alegre, ano 1, n. 1, p. 89-114, 1999. MARIZ, Cecília Loreto. Alcoolismo, gênero e pentecostalismo. Religiáo \& Sociedade, Rio de Janeiro, v. 16, n. 3, p. 80-93, 1994. 
MARTIN, David. Tongues of fire: the explosion of Protestantism in Latin America. Oxford: Blackwell, 1990.

MIGUEZ, Daniel. To help you find God: the making of a Pentecostal identity in a Buenos Aires suburb. 1997. Tese (Doutorado em Antropologia Social) - Universidade Livre de Amsterdam, Amsterdam, 1997.

OLIVEIRA, Marco Antônio de. O protestantismo em face da pentecostalização dos movimentos evangélicos brasileiros. In: BINGEMER, Maria Clara Lucchetti; ANDRADE, Paulo Fernando Carneiro de (org.). O censo e as religióes no Brasil. Rio de Janeiro: Ed. PUC-Rio: Reflexão, 2014. p. 141-148.

ORO, Ari Pedro. Algumas interpelações do Pentecostalismo no Brasil. Horizonte, Belo Horizonte, v. 9, n. 22, p. 383-395, 2011.

ORO, Ari Pedro. Avanço pentecostal e reação católica. Petrópolis: Vozes, 1995.

PARKER, Cristian. Religião popular e protesto contra a opressão: o exemplo chileno. Concilium, Petrópolis, n. 206, p. 26-40, 1986.

QUEIROZ, Christina. Fé pública. Pesquisa FAPESP, ano 20, n. 286, p. 12-21, dez. 2019.

SANCHIS, Pierre. O repto pentecostal à "cultura católico-brasileira”. In: ANTONIAZZI, Alberto et al. Nem anjos nem demônios: interpretações sociológicas do pentecostalismo. Petrópolis: Vozes, 1994. p. 34-63.

STEIL, Carlos Alberto; TONIOL, Rodrigo. O catolicismo e a Igreja Católica no Brasil à luz dos dados sobre religião no Censo de 2010. In: BINGEMER, Maria Clara Lucchetti; ANDRADE, Paulo Fernando Carneiro de (org.). $O$ censo e as religióes no Brasil. Rio de Janeiro: Ed. PUC-Rio: Reflexão, 2014. p. 11-30.

STOLL, David. Is Latin America turning protestant? Berkeley: University of California Press, 1990. 
WILLEMS, Emilio. Followers of the new faith: culture change and the rise of Protestantism in Brazil and Chile. Nashville: Vanderbilt University Press, 1967.

Recebido em: 28/03/2020

Aprovado em: 28/03/2020 

ARTIGOS 